\title{
A New Technique to Treat Facet Joint Pain With Pulsed Radiofrequency
}

\author{
Pietro Martino Schianchi ${ }^{1, *}$ \\ ${ }^{1}$ Department of Pain Management, S. Anna Clinic, Lugano, Switzerland \\ ${ }^{*}$ Corresponding author: Pietro Martino Schianchi, Department of Pain Management, S. Anna Clinic, Lugano, Switzerland. Tel: +41-919233978, Fax:+41-919238917, E-mail: p.schianchi@ \\ bluewin.ch
}

Received: July 6, 2014; Revised: October 5, 2014; Accepted: October 13, 2014

\begin{abstract}
Introduction: Facet joint pain affects $5 \%$ to $15 \%$ of the population with low back pain and the prevalence increases with age due to progression of arthritis. While conservative treatments are often unsuccessful, the scientific evidence on minimally invasive therapies such as intra-articular steroid infiltration and continuous and pulsed radiofrequency (PRF) of the medial branches is contradictory. Since PRF has recently been reported to successfully treat joint pain, a new application of this method is proposed for facetogenic lumbar pain via an intra-articular subcapsular approach. Here we reported two cases with successful treatment.

Case Presentation: A 71-year-old patient presented because of persisting pain in the left gluteal region radiating to the lateral thigh and calf when standing. Anti-inflammatory drugs produced only short-lasting insufficient relief. A 52-year-old employee was admitted in June 2012 because of axial lower lumbar pain with intermittent diffuse radiation to the right lower extremity that worsened during walking and lying down despite receiving analgesics and physiotherapy.

Conclusions: A new approach to treat lumbar facet joint pain with PRF is simple to perform and without serious complications. In view of the good long-lasting results obtained with the two reported cases, randomized control trials are necessary to validate this new approach.
\end{abstract}

Keywords:Zygapophyseal Joint; Low Back Pain; Pulsed Radiofrequency Treatment; Cytokines; Chronic Pain; Joints

\section{Introduction}

Goldthwait (1) first recognized in 1911 that facet joints are an important source of pain in the lumbar region. Interventional treatment of facet joint pain was realized in 1975 by Shealy (2) using conventional radiofrequency (RF) to burn the medial branches. Although this procedure is still used today, scientific evidence of its efficacy remains contradictory. Intra-articular (IA) steroid injections, when effective, have a short duration, and the results of controlled studies are disappointing (3).

The use of pulsed RF (PRF) at the medial branches to treat facet joint pain has been practiced since its introduction by Sluijter in 1996. Two randomized trials have compared PRF and RF effects in denervation of the facet joints. Tekin et al. (4) showed that both treatments had comparable results at six months, but the benefit was maintained for one year only in the RF group. Kroll et al. (5) showed no difference between the RF and PRF groups in relative improvement in either pain (visual analog scale, VAS) or disability (Oswestry Low Back Pain and Disability Score) scores. A prospective study by Mikeladze et al. (6) in 2003 showed that 68 patients who were treated with PRF experienced 50\% or more pain relief for at least three months.

In 2006, a new application of PRF was introduced; applying IA PRF in a knee with osteoarthritis (OA) could produce pain relief. This initial attempt to treat joint pain with PRF by Teixeira (personal communication) was fol- lowed by a report of six cases by Sluijter et al. (7) in 2008. In 2013, Schianchi et al. (8) published a retrospective study of 57 consecutive patients treated with IA PRF in small and large joints. The success rate ranged from $62.5 \%$ for large joints (mean follow-up, 14.5 months) to $90 \%$ for small joints (mean follow-up, 8.5 months). Since facet joints are true synovial joints with a structure similar to larger joints, we applied PRF into the joint space, inserting the cannula under the capsule. This new approach was motivated by the good results obtained with PRF in other joints. We report two patients who had long-lasting pain relief after treatment with IA PRF.

As a new method to treat painful lumbar facet joints, IA PRF is simple to perform and without relevant complications. The use of fluoroscopy is necessary to visualize the target point at the tip of the superior articular process (SAP) under the capsule and check the depth of the cannula, which lies parallel to the SAP. The technique is demonstrated in Figures 1 - 3. We used a 22-G SMK C-10 PRF cannula with a $10-\mathrm{mm}$ active tip to produce wider electric fields from the non-insulated portion. We believe that this position allows better exposure to the electric fields that are generated along the shaft of the cannula. Our current parameters are: $40 \mathrm{~V}$; pulse width, $10 \mathrm{~ms}$; frequencies, $2 \mathrm{~Hz}$, or $5 \mathrm{~ms}$ and $5 \mathrm{~Hz}$ applied for 10 minutes. Correct positioning of the needle within the capsule is usually associated with an impedance $<300 \Omega$.

Copyright (C) 2015, Iranian Society of Regional Anesthesia and Pain Medicine(ISRAPM). This is an open-access article distributed under the terms of the Creative Commons Attribution-NonCommercial 4.0 International License (http://creativecommons.org/licenses/by-nc/4.0/) which permits copy and redistribute the material just in noncommercial usages, provided the original work is properly cited. 


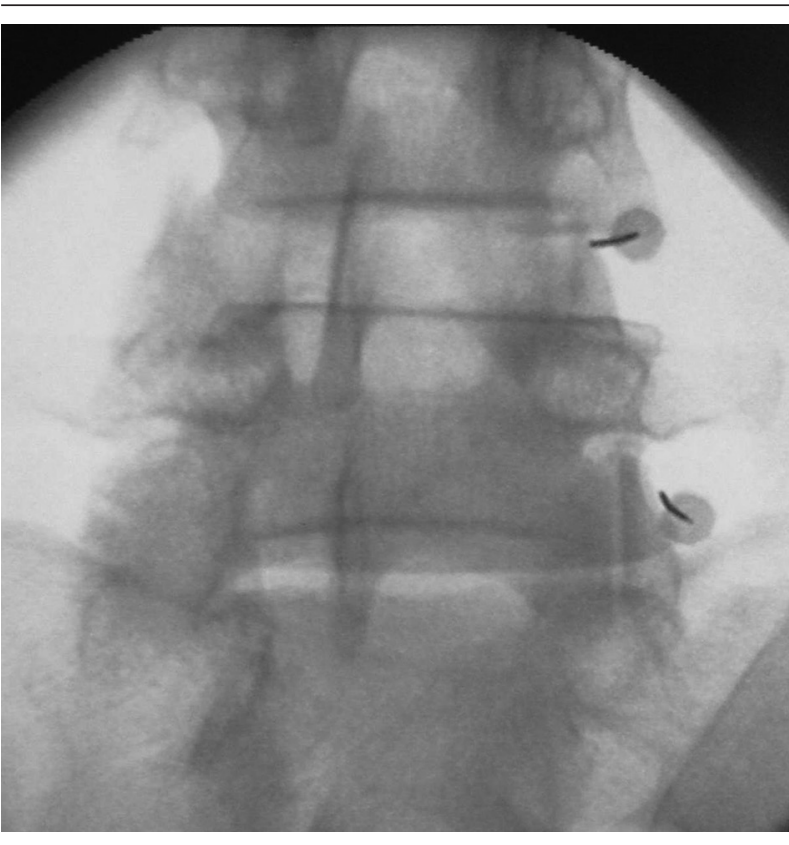

Figure 1. Anterior-Posterior Fluoroscopic View Showing the PRF Cannula Directed Towards the Tip of the Superior Articular Process of Facet joint

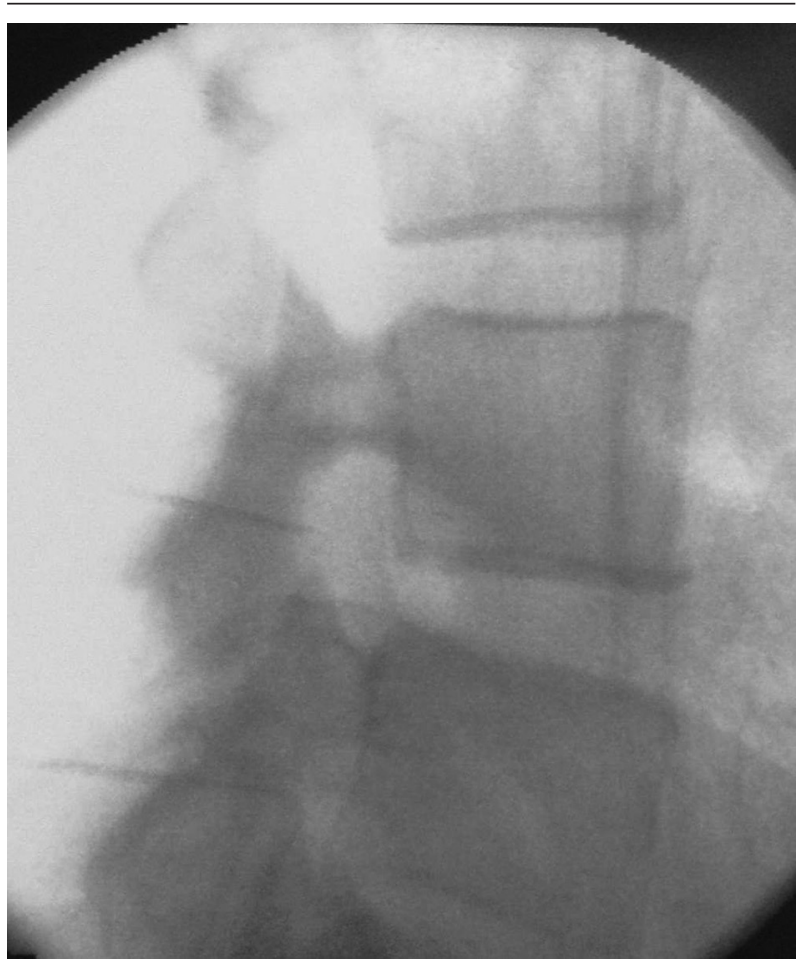

Figure 2. Lateral Fluoroscopic View Showing the PRF Cannula Adjacent to the Facet joint and Under the Articular Capsule

We chose the tip of the SAP as a landmark because the SAP is readily visible on fluoroscopy and at this point, the capsule is abundant and loose, forming a pouch that balloons upward toward the base of the next transverse process (9), allowing easier access to the subcapsular space.
Due to the complex, multisegmental innervation of the facet joints, selective diagnostic medial branch blocks are needed to confirm the clinical diagnosis. The subcapsular infiltration of a local anesthetic with contrast medium should be performed with caution, as local anesthetics can be chondrotoxic (10).

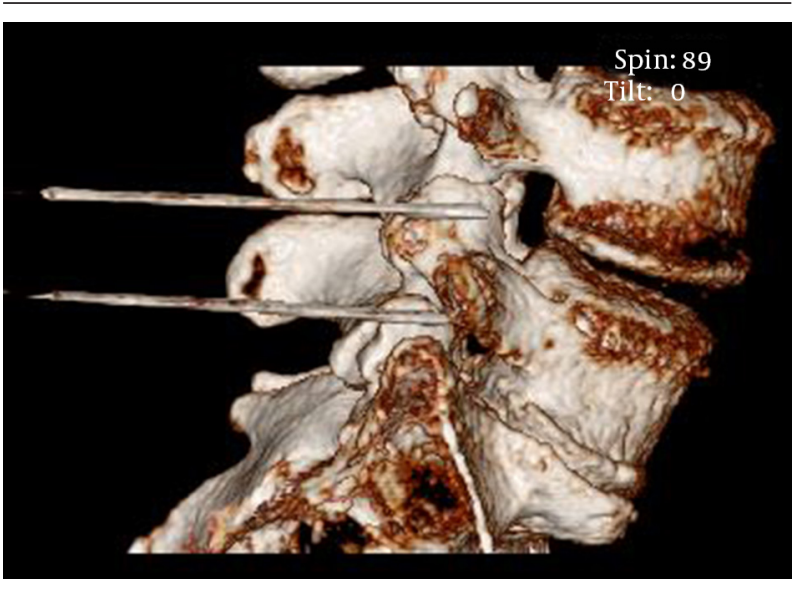

Figure 3. Three-Dimensional Computed Tomography Reconstruction Im age of the Facet joints With PRF Cannula Adjacent to the Facet joint

\section{Case Presentation}

\subsection{Case 1}

A 71-year-old patient presented with persisting pain in the left gluteal region radiating to the lateral thigh and calf when standing. Anti-inflammatory drugs produced only short-lasting insufficient relief. The clinical examination was suggestive of upper lumbar facetogenic pain. Magnetic resonance imaging (MRI) showed multisegmental spondylarthrosis.

Since the pain radiated below the knee, a selective diagnostic L5 nerve-root block was performed to rule out radicular irritation, with a negative result. Selective diagnostic blocks of the left medial branches of L1 through L3 reduced the pain by at least $50 \%$. The pain remained stable for 4.5 months without medication. When the pain increased, IA PRF of the left facet joints L1/L2 and L2/L3 was performed in March 2012. The VAS score improved by 50\% after ten days and by $85 \%$ after one month. The patient continued to experience satisfactory pain relief for two years.

\subsection{Case 2}

A 52-year-old employee was admitted in June 2012 with axial lower lumbar pain with intermittent diffuse radiation to the right lower extremity that worsened during walking and lying down despite analgesics and physiotherapy since 2004. On clinical examination, the facet joints were tender. MRI revealed a bulging disc at the level L4/L5, grade I pseudospondylolisthesis, and Modic II 
changes of the L4 and L5 vertebral bodies.

Selective diagnostic blocks of the right medial branches of L3 through L5 produced almost complete pain relief for three months. In September 2012, IA PRF at L4/L5 and L5/S1 was performed. Since similar pain was also present on the left side, IA PRF was done at L3/L4, L4/L5, and L5/S1 on that side in November 2012. Both procedures were successful, with $80 \%$ pain relief for over a year.

\section{Discussion}

The prevalence of facet joint pain is estimated to range from $5 \%$ to $15 \%$ in the population with low back pain (11). Because arthritis is a prominent cause of lumbar facetogenic pain, the incidence increases with age. It has recently become evident that the inflammatory cytokine network plays a major role in the pathophysiology of OA (12).

Inflammatory cytokines like interleukin 6 (IL-6), tumor necrosis factor $\alpha$ (TNF $\alpha$ ), and interleukin $1 \beta$ (IL-1 $\beta$ ) can be found in facet joint tissues in degenerative lumbar disorders (13) and in osteoarthritic joints in general (1214). Since facet joints are true synovial joints, the same as the articulations of the upper and lower extremities, it is reasonable to believe that their metabolism is not significantly different, particularly with regard to chondrocytes. In osteoarthritic joints, the production of inflammatory cytokines and matrix-degrading enzymes disturbs chondrocyte metabolism, leading to cartilage degradation. Cartilaginous changes elicit intense pathologic remodeling in the subchondral bone (14) and further stimulate the inflammatory process.

Produce pain relief in small and large joints by PRF has contributed to new concepts of its mode of action (15). In contrast to conventional RF, the action of PRF is not limited to neural structures. In view of the good results obtained with joint pain (7, 8), Sluijter et al. (15) have postulated a local or regional effect of the electric fields produced by PRF on immune cells and thus, influencing the nociceptive process itself rather than merely the afferent innervation. The electric fields that are involved in this process might be quite low. Maretto et al. (16) recently demonstrated that applying PRF at a uniform field strength of $200 \mathrm{~V} / \mathrm{m}$ to monocytes induces biological activity of TNF- $\alpha$.

The electric fields that are generated during PRF are very strong at the tip of the cannula, but fall off rapidly over the first $0.1 \mathrm{~mm}$ from the electrode tip. There is an extremely small and negligible risk of permanent damage to a nerve or any other structure during procedure $(15,17,18)$.

Of greater importance are the electric fields around the cylindrical part of the electrode: they are weaker (50000 $\mathrm{V} / \mathrm{m}$ ) than at the tip, but their extent is broader, providing a wide area where low electric fields with their pronounced biological effect are available. These could ex- plain the good results obtained, in particular, with IA PRF (15). To validate the efficacy and compare the duration of effect of this new technique with other approaches to lumbar facet pain, further experience and randomized controlled trials are necessary.

\section{Acknowledgements}

The author is particularly indebted to Professor Dr. ME Sluijter for reading and correcting some parts of the manuscript and to Dr. SE Balogh for editorial assistance.

\section{References}

1. Goldthwait JE. The lumbo-sacral articulation; An explanation of many cases of" lumbago,"" sciatica" and paraplegia. Boston Med Surg J.1911;164(11):365-72.

2. Shealy CN. Percutaneous radiofrequency denervation of spinal facets. Treatment for chronic back pain and sciatica.J Neurosurg. 1975;43(4):448-51.

3. Lilius G, Laasonen EM, Myllynen P, Harilainen A, Salo L. [Lumbar facet joint syndrome. Significance of non-organic signs. A randomized placebo-controlled clinical study]. Rev Chir Orthop Reparatrice Appar Mot. 1989;75(7):493-500.

4. Tekin I, Mirzai H, Ok G, Erbuyun K, Vatansever D. A comparison of conventional and pulsed radiofrequency denervation in the treatment of chronic facet joint pain. Clin J Pain. 2007;23(6):524-9.

5. Kroll HR, Kim D, Danic MJ, Sankey SS, Gariwala M, Brown M. A randomized, double-blind, prospective study comparing the efficacy of continuous versus pulsed radiofrequency in the treatment of lumbar facet syndrome. J Clin Anesth. 2008;20(7):534-7.

6. Mikeladze G, Espinal R, Finnegan R, Routon J, Martin D. Pulsed radiofrequency application in treatment of chronic zygapophyseal joint pain. Spine J. 2003;3(5):360-2.

7. Sluijter ME, Teixeira A, Serra V, Balogh S, Schianchi P. Intra-articular application of pulsed radiofrequency for arthrogenic pain-report of six cases. Pain Pract. 2008;8(1):57-61.

8. Schianchi PM, Sluijter ME, Balogh SE. The Treatment of Joint Pain with Intra-articular Pulsed Radiofrequency. Anesth Pain Med. 2013;3(2):250-5

9. Bogduk N. Clinical Anatomy of the Lumbar Spine and Sacrum.: Elsevier/Churchill Livingstone; 2005.

10. Piper SL, Kramer JD, Kim HT, Feeley BT. Effects of local anesthetics on articular cartilage. Am J Sports Med. 2011;39(10):2245-53.

11. Van Kleef M, Vanelderen P, Cohen SP, Lataster A, Van Zundert J, Mekhail N. Pain originating from the lumbar facet joints. Pain Practice. 2010;10(5):459-69.

12. Kapoor M, Martel-Pelletier J, Lajeunesse D, Pelletier JP, Fahmi H. Role of proinflammatory cytokines in the pathophysiology of osteoarthritis. Nat Rev Rheumatol. 2011;7(1):33-42.

13. Igarashi A, Kikuchi S, Konno S. Correlation between inflammatory cytokines released from the lumbar facet joint tissue and symptoms in degenerative lumbar spinal disorders. J Orthop Sci. 2007;12(2):154-60.

14. Lee AS, Ellman MB, Yan D, Kroin JS, Cole BJ, van Wijnen AJ, et al. A current review of molecular mechanisms regarding osteoarthritis and pain. Gene. 2013;527(2):440-7.

15. Sluijter ME, Imani F. Evolution and mode of action of pulsed radiofrequency. Anesth Pain Med. 2013;2(4):139-41.

16. Maretto F, Vennik M, Albers KI, van Duijn B. TNFalpha secretion of monocytes exposed to pulsed radiofrequency treatment: a possible working mechanism of PRF chronic pain management. Pain Pract. 2014;14(5):399-404.

17. Erdine S, Bilir A, Cosman ER, Cosman ER, Jr.. Ultrastructural changes in axons following exposure to pulsed radiofrequency fields. Pain Pract. 2009;9(6):407-17.

18. Erdine S, Yucel A, Cimen A, Aydin S, Sav A, Bilir A. Effects of pulsed versus conventional radiofrequency current on rabbit dorsal root ganglion morphology. Eur J Pain. 2005;9(3):251-6. 